\title{
TESTE DE FRIO PARA AVALIAÇÃO DO POTENCIAL FISIOLÓGICO DE SEMENTES DE ALGODÃO
}

\author{
Marcelo Hissnauer Miguel|,3*; Mariane Victorio de Carvalho ${ }^{1,4}$; Osmar Paulo Beckert1,4; Júlio \\ Marcos Filho ${ }^{2,4}$ \\ ${ }^{1}$ Pós-Graduandos em Fitotecnia - USP/ESALQ. \\ ${ }_{3}^{2}$ Depto. de Produção Vegetal - USP/ESALQ, C.P. 9 - CEP: 13418-900 - Piracicaba, SP. \\ ${ }^{3}$ Bolsista FAPESP. \\ ${ }^{4}$ Bolsista CNPq. \\ *Autor correspondente <mhmiguel@carpa.ciagri.usp.br>
}

\begin{abstract}
RESUMO: O teste de frio tem sido usado principalmente para sementes de milho. Porém, seu uso em outras espécies como feijão, soja, algodão e ervilha tem crescido significativamente em todo o mundo. No entanto, ressalta-se a necessidade da padronização de metodologias do teste de frio de acordo com as características de cada espécie a ser testada. Dessa forma, com o objetivo de determinar a eficiência do teste de frio na avaliação do potencial fisiológico de sementes de algodão, cinco lotes do cultivar Delta Pine - Acala 90, deslintados quimicamente, foram submetidos a diferentes procedimentos: caixa com terra, rolo de papel com terra e rolo de papel sem terra, variando-se o período de exposição (três, cinco e sete dias) das sementes à baixa temperatura $\left(10^{\circ} \mathrm{C}\right)$. Paralelamente, as sementes foram submetidas aos testes de condutividade elétrica e de envelhecimento acelerado, para comparação com os resultados obtidos nos diferentes procedimentos do teste de frio. A utilização de rolo de papel sem terra, com cinco e sete dias de exposição ao frio, permitiu classificar de maneira mais consistente, os lotes de sementes de algodão, em função do potencial fisiológico, com relação às informações obtidas nos testes de condutividade elétrica e de envelhecimento acelerado. $\mathrm{O}$ uso desse procedimento, com cinco dias de exposição a $10^{\circ} \mathrm{C}$, pode ser indicado para avaliação do vigor de sementes de algodão.
\end{abstract}

Palavras-chave: Gossypium hirsutum, sementes, análise, vigor

\section{COLD TEST EVALUATION OF THE PHYSIOLOGICAL POTENTIAL OF COTTON SEEDS}

\begin{abstract}
The cold test has been employed mainly for corn seeds but its use is steadly growing for crops as cotton, soybean, common bean, pea, etc. It seems also to be true that for each of these crops the procedures of the cold test should be standardized. Thus, seed vigor of five cotton delinted seed lots was evaluated by means of different procedures of the cold test: soil plastic boxes, soil in rolled paper towel and rolled paper towel without soil. Seeds were exposed to $10^{\circ} \mathrm{C}$ during three, five and seven days. Simultaneously, seeds were submitted to the electrical conductivity and the accelerated aging vigor tests to make a comparison with the cold test. The paper towel method for five and seven days allowed, consistently, the detection of different vigor classes of seed lots when compared to the other cold test procedures as well as to the electrical conductivity and accelerated aging tests. The use of the paper towel as substratum and the exposure of seeds to $10^{\circ} \mathrm{C}$ for five days is therefore indicated as a reliable method for cotton seed vigor evaluation.

Key words: Gossypium hirsutum, seed analysis, physiological quality, cold test
\end{abstract}

\section{INTRODUÇÃO}

O uso de sementes com potencial fisiológico elevado é fundamental na obtenção de resultados satisfatórios em culturas de expressão econômica. Uma das ferramentas essenciais para alcançar esses resultados é a análise de sementes.

O desempenho das sementes é determinado rotineiramente pelo teste padrão de germinação. Porém, nota-se que há algum tempo, pesquisadores, produtores de sementes e agricultores, não têm se mostrado satisfeitos com o uso exclusivo de informações fornecidas por esse teste que identifica o potencial fisiológico das sementes, sob condições ideais (Marcos Filho et al., 1987). Marcos Filho (1999a) e Carvalho \& Nakagawa (2000) relataram que as condições ambientais exercem influência acentuada sobre a manifestação do potencial fisiológico das sementes e, portanto, se a semeadura for realizada em condições ambientais desfavoráveis, a emergência de plântulas normais pode ser inferior à determinada em laboratório.

Portanto, há necessidade da inclusão de testes, em programas de controle de qualidade, que permitam, pelo menos, identificar diferenças no potencial fisiológico de lotes com alta germinação ou viabilidade, além de detectar possíveis diferenças no potencial de desempenho entre lotes com germinação ou viabilidade semelhantes (Marcos Filho, 1999a). Nesse sentido, os testes de vigor, têm se constituído em ferramentas de uso cada vez mais rotineiro, pela indústria de sementes e pesquisadores. 
O teste de frio, que tem como princípio básico a exposição das sementes a baixa temperatura, alta umidade e agentes patogênicos (quando se utiliza terra procedente de áreas de cultivo da espécie), pode funcionar como instrumento de grande valor para a seleção prévia de lotes de sementes, quanto ao seu desempenho, em uma ampla faixa de condições ambientais. Esse é considerado um teste de resistência, pois o lote de sementes que melhor resistir às condições adversas é considerado o de maior potencial fisiológico. De forma geral, se os resultados do teste de frio se aproximarem dos obtidos no teste padrão de germinação, há grande possibilidade desse lote apresentar capacidade para germinar sob ampla variação das condições de umidade e temperatura do solo (Cicero \& Vieira, 1994).

Atualmente, o teste de frio é mais utilizado para a cultura do milho; no entanto, em função da confiabilidade dos resultados fornecidos, há interesse em padronizá-lo para outras espécies. A literatura indica carência de pesquisas com sementes de algodão. Existem trabalhos empregando o teste de frio na avaliação do potencial fisiológico de sementes de algodão (Krzyzanowski, 1980), feijão vagem (Samimy et al., 1987), soja (Kulik et al., 1982, Vieira et al., 1992 e Miguel \& Cicero 1999), feijão (Miguel \& Cicero, 1999); porém os estudos com relação aos aspectos metodológicos e sua utilização, têm se concentrado nas sementes de milho.

A pesquisa tem apontado algumas variações para a metodologia do teste, como a utilização do papel toalha com terra (Hoppe, 1956; Crosier, 1957), reduzindo a quantidade de substrato e o espaço necessário, que muitas vezes se tornam fatores limitantes para os laboratórios. Loeffler et al. (1985), sugeriram a utilização de rolos de papel toalha sem terra; esta variação, quando sensível na determinação do potencial fisiológico das sementes, é interessante porque, além de reduzir o espaço, elimina o uso de terra como substrato, minimizando os seus inconvenientes, relativos a higiene e dificuldades na padronização.

Há, também, tentativas no sentido de se alterar a temperatura e o período de exposição, diminuindo, assim, o período de tempo necessário para a execução do teste (Miguel \& Cicero, 1999); essas iniciativas procuram atender, a necessidade do mercado que, freqüentemente, exige respostas rápidas para subsidiar decisões.

Assim, o presente trabalho teve o objetivo de estudar diferentes procedimentos para condução do teste de frio, comparativamente a outros testes utilizados para avaliar o potencial fisiológico de sementes de algodão.

\section{MATERIAL E MÉTODOS}

A pesquisa foi conduzida no Laboratório de Análise de Sementes (LAS) e em área experimental do
Departamento de Produção Vegetal da Escola Superior de Agricultura "Luiz de Queiroz" (LPV/ESALQ), Universidade de São Paulo (USP), no município de Piracicaba - SP.

Foram utilizadas sementes de algodão deslintadas quimicamente, cultivar Delta Pine - Acala 90, representadas por cinco lotes com diferentes potenciais fisiológicos, armazenados em condições de ambiente não controlados, durante o período experimental.

\section{METODOLOGIAS UTILIZADAS PARA O TESTE DE FRIO}

Teste de frio com terra - semeadura em caixas plásticas Utilizou-se substrato resfriado a $10^{\circ} \mathrm{C}$ (Caseiro \& Marcos Filho, 2000), constituído de $3 / 4$ de areia e 1/4 de terra, proveniente de área cultivada com algodão. A mistura foi colocada em caixas plásticas $(47 \mathrm{~cm} \times 30 \mathrm{~cm}$ $x 11 \mathrm{~cm})$, onde se procedeu a distribuição de quatro repetições de 50 sementes de cada lote. Em seguida, as sementes foram cobertas com uma camada de, aproximadamente, $3 \mathrm{~cm}$ do substrato; este foi irrigado com água, também a $10^{\circ} \mathrm{C}$, até atingir $60 \%$ da sua capacidade de retenção. As sementes permaneceram em câmara fria durante três $\left(\mathrm{Cx} 3 \mathrm{D} 10^{\circ} \mathrm{C}\right)$, cinco (Cx 5D $10^{\circ} \mathrm{C}$ ) e sete dias $\left(\mathrm{Cx} 7 \mathrm{D} 10^{\circ} \mathrm{C}\right)$, a $10^{\circ} \mathrm{C}$.

Em seguida, as caixas foram colocadas sob condições ambientais não controladas do LAS/LPV/USP/ ESALQ, onde permaneceram por sete dias; nesta ocasião foi realizada a contagem das plântulas emersas, conforme Cicero \& Vieira (1994) e Barros et al. (1999). Os resultados foram expressos em porcentagem média por lote.

\section{Teste de frio em rolo de papel com terra}

Foram distribuídas quatro repetições de 50 sementes de cada lote, sobre duas folhas de papel toalha Germitest e cobertas com uma fina camada de terra, (aproximadamente $1 \mathrm{~cm}$ ) proveniente de área cultivada com algodão; a seguir, o conjunto foi coberto com uma terceira folha e enrolado. As folhas de papel Germitest, foram previamente umedecidas com quantidade de água equivalente a três vezes o seu peso seco. Os rolos foram colocados em caixas plásticas, vedadas e, em seguida, mantidos durante três (RPCT 3D $10^{\circ} \mathrm{C}$ ), cinco (RPCT 5D $10^{\circ} \mathrm{C}$ ) e sete dias (RPCT 7D $10^{\circ} \mathrm{C}$ ), a $10^{\circ} \mathrm{C}$. Decorridos os respectivos períodos, os rolos foram transferidos para germinador, a $25^{\circ} \mathrm{C}$, por três dias e, em seguida, efetuaram-se as contagens de plântulas normais. Os resultados foram expressos em porcentagem média por lote.

\section{Teste de frio em rolo de papel sem terra}

Os procedimentos foram semelhantes aos descritos no item anterior, mas as sementes não foram cobertas por uma fina camada de terra; a quantidade de água, utilizada para o umedecimento do substrato, foi equivalente a 2,5 vezes o peso do papel toalha. Os rolos foram mantidos a três (RPST $3 \mathrm{D} 10^{\circ} \mathrm{C}$ ), cinco (RPST 5D $10^{\circ} \mathrm{C}$ ) e sete dias (RPST 7D $10^{\circ} \mathrm{C}$ ). 
Outras determinações utilizadas para avaliar o potencial fisiológico dos lotes de sementes de algodão.

Germinação - conduzido com quatro repetições de 50 sementes, para cada lote, em rolos de papel toalha, em germinador regulado a $25^{\circ} \mathrm{C}$. A quantidade de água adicionada foi equivalente a 2,5 vezes o peso do substrato seco, visando adequado umedecimento, e consequentemente uniformização do teste. Segundo os critérios estabelecidos nas Regras de Análises de sementes (Brasil, 1992), as contagens devem ser realizadas aos $4^{\circ}$ e $12^{\circ}$ dias após a semeadura. No entanto, segundo metodologia proposta por Novembre (1994), Novembre \& Marcos Filho (1999), contagens realizadas nos $3^{\circ}$ e $5^{\circ}$ dias após a semeadura apresentam resultados semelhantes, porém com considerável economia de tempo. Dessa forma, para o presente experimento, as contagens foram realizadas no $3^{\circ}$ e $5^{\circ}$ dias após a semeadura. Os resultados foram expressos em porcentagem média por lote.

Primeira contagem de germinação - conduzida juntamente com o teste padrão de germinação, registrando-se a porcentagem de plântulas normais da primeira contagem do referido teste.

Envelhecimento acelerado - realizado com quatro repetições de 50 sementes de cada lote, empregandose o método citado por Marcos Filho (1999b), sob condições controladas de temperatura e umidade relativa do $\operatorname{ar}\left(41^{\circ} \mathrm{C}\right.$ e $100 \%$ UR), durante 48 horas. Decorrido esse período, as sementes foram colocadas em rolos de papel Germitest e postas a germinar de maneira semelhante à descrita para o teste padrão de germinação. A interpretação do teste foi realizada no $3^{\circ}$ dia após a semeadura. Os resultados foram expressos em porcentagem média por lote.

Condutividade elétrica - conduzido através do sistema de massa, com quatro repetições de 50 sementes não selecionadas para cada lote. As sementes foram pesadas com precisão de duas casas decimais e, em seguida, colocadas em copos plásticos, com $75 \mathrm{ml}$ de água destilada e mantidas em germinador a $25^{\circ} \mathrm{C}$ constantes. Após 24 horas de embebição, a condutividade elétrica da solução foi determinada em condutivímetro (DIGIMED - DM 31) de acordo com metodologia descrita por Vieira \& Krzyzanowski (1999).

Delineamento estatístico - $O$ delineamento experimental empregado foi o inteiramente casualizado com nove tratamentos correspondentes aos procedimentos utilizadas no teste de frio. Os dados porcentuais foram transformados em Arco Seno $(\% / 100)^{0,5}$. A análise da variância, para os procedimentos do teste de frio, foi realizada dentro de cada procedimento para os cinco lotes. $\mathrm{Na}$ execução das análises estatísticas foi utilizado o "Sistema de Análise Estatística para Microcomputadores - SANEST (Zonta \& Machado, 1984)".

\section{RESULTADOS E DISCUSSÃO}

Os dados referentes ao potencial fisiológico dos cinco lotes de sementes de algodão, cultivar Delta Pine - Acala 90, podem ser observados na TABELA 1. Os testes utilizados foram sensíveis para distinguir diferenças e indicar uma tendência de separação dos lotes, de acordo com o potencial fisiológico, classificando o lote 2 como o mais vigoroso. Em seguida, aparece o lote 1 , que nos testes de germinação e condutividade elétrica foi semelhante ao lote 2 , porém nos testes de primeira contagem de germinação e envelhecimento acelerado apresentou valores inferiores. O lote 3 apresentou os menores valores nos testes de germinação, primeira contagem de germinação e envelhecimento acelerado, porém, no teste de condutividade elétrica mostrou-se semelhante aos lotes 1 e 2. No caso do lote 4, este mostrou-se como o menos vigoroso nos testes de envelhecimento acelerado e condutividade elétrica e, nos testes de germinação e primeira contagem de germinação, como intermediário. $\mathrm{O}$ lote 5 apresentou os menores valores nos testes de germinação e primeira contagem de germinação, e intermediário, nos testes de envelhecimento acelerado e condutividade elétrica. De maneira geral, observou-se que os lotes 1 e 2 mostraram valores mais elevados nos testes estudados, podendo ser considerados os mais vigorosos, enquanto que, os lotes 3,4 e 5 mostraram potencial fisiológico inferior aos lotes 1 e 2 .

Com relação ao teste de frio, os procedimentos que envolveram caixa com terra foram muito drásticos, impossibilitando uma avaliação adequada dos lotes, tendo como conseqüência, a não separação em diferentes níveis de vigor (TABELA 2). As sementes avaliadas nesses procedimentos não germinaram ou, se germinaram, foram em pequenas porcentagens. A maioria encontrava-se totalmente envolvida por uma massa de fungos, fator que culminou com a morte destas. Deve se destacar que as sementes não sofreram tratamento fungicida e a semeadura foi realizada em substrato proveniente de campo de produção, o qual provavelmente deveria conter microrganismos de solo. Isso contribuiu significativamente para a severidade do teste e grande variação nos resultados, dificultando o uso desses procedimentos de caixa com terra. Tal fato pode indicar maior sensibilidade de sementes de algodão, a determinadas condições de estresse, quando comparadas a outras espécies. Estudos realizados por diversos pesquisadores (Loeffler et al., 1985; Molina et al., 1987; Medina \& Marcos Filho, 1990) indicaram que o procedimento do teste de frio tradicional (caixa com terra) apesar de ser o mais severo, por oferecer condições mais estressantes, foi o mais sensível para separar lotes de sementes de milho com diferentes níveis de vigor, quando comparado a outros métodos. No entanto, quando os patógenos do substrato foram eliminados através da esterilização, não houve 
diferenças significativas entre os procedimentos avaliados (caixa com terra, rolo de papel com terra e bandeja) (Woltz et al., 1998).

Os procedimentos de rolo de papel com terra, apesar de utilizarem como substrato terra proveniente de campos de produção, foram menos drásticos que os procedimentos de caixa com terra, possibilitando uma separação adequada dos lotes em níveis de vigor (TABELA 2). Os lotes 2 e 1 apresentaram valores mais elevados, os lotes 3 e 5 apresentaram os menores valores e o lote 4 valores intermediários. Embora tenha sido possível a distinção dos lotes, quanto ao potencial fisiológico, apenas o procedimento em que o período de exposição ao frio foi de três dias, ocorreram diferenças estatísticas na distinção dos lotes. Esses resultados, quando comparados com os obtidos nos outros testes realizados (TABELA 1), se confirmam parcialmente, verificando-se uma classificação dos lotes 1 e 2 , como os melhores e uma tendência dos lotes 3 e 5 , como os piores, pois apresentam resultados semelhantes aos testes de germinação e primeira contagem de germinação.

A porcentagem de plântulas normais no rolo de papel com terra, decresceu à medida que se aumentou o período de exposição ao frio de três para sete dias (TABELA 2). Bruggink et al. (1991), trabalhando com sementes de milho, em caixa com terra (metodologia tradicional), obtiveram valores decrescentes de plântulas normais com o aumento do período de exposição ao frio, principalmente para lotes de baixo vigor, pois neste caso, as sementes permaneceriam expostas aos agentes patogênicos presentes no solo, por um período maior, lembrando que a temperatura e o potencial fisiológico das sementes, são fatores que atuam diretamente na velocidade de germinação. $O$ tratamento das sementes com fungicida ou o uso de terra esterilizada, poderia reduzir os problemas causados, ao processo germinativo, pelo aumento do período de exposição ao frio (Woltz et al., 1998).

Os procedimentos de rolo de papel sem terra apresentaram-se como os menos severos, permitindo também a classificação dos lotes, segundo o potencial fisiológico (TABELA 2).

O teste de frio sem a utilização de terra, avalia diretamente os efeitos da baixa temperatura e da alta umidade, sem a interferência de outros fatores bióticos (Loeffler et al., 1985). Nesse caso, não existe a microbiota do solo, o que facilita a padronização da metodologia e a uniformidade dos resultados obtidos (Burris \& Navratil, 1979). Apesar dos efeitos serem menos drásticos que os observados em testes com terra, a simplicidade de sua execução e a maior precisão dos resultados justificam o seu uso. Este pode ser um teste prático para avaliar o efeito de estresse causado pelo frio sobre a germinação, pois requer menos espaço e tempo do que testes com areia ou outro tipo de solo (Waters \& Blanchette, 1983).
A classificação ("ranqueamento") dos lotes com três e sete dias de exposição ao frio, foi semelhante ao uso de rolo de papel com terra (TABELA 2), ou seja, os lotes 2 e 1 como os mais vigorosos, o lote 4 intermediário e os lotes 3 e 5 como os menos vigorosos. Para a metodologia com cinco dias de exposição ao frio, a separação foi praticamente semelhante às obtidas nos testes de envelhecimento acelerado e condutividade elétrica. Essa característica é de grande importância, uma vez que existe confirmação e coerência entre os diferentes testes, o que é fundamental para se obterem informações completas sobre o potencial fisiológico das sementes.

TABELA 1 - Germinação (G), primeira contagem de germinação (PCG), envelhecimento acelerado (EA) e condutividade elétrica (CE) dos lotes de sementes de algodão, cultivar Delta Pine Acala 90.

\begin{tabular}{|c|c|c|c|c|}
\hline Lote & G & EA & PCG & CE \\
\hline & ------- & - & --.-- & $\mu S \mathrm{~cm}^{-1} \mathrm{~g}^{-1}$ \\
\hline L1 & $80 a b$ & $75 \mathrm{bc}$ & $68 \mathrm{~b}$ & $249 a$ \\
\hline L2 & $88 a$ & $88 a$ & $83 a$ & $233 a$ \\
\hline L3 & $63 c$ & $61 \mathrm{~cd}$ & $55 \mathrm{bc}$ & $276 a$ \\
\hline L4 & $77 \mathrm{~b}$ & $76 a b$ & $46 \mathrm{c}$ & $370 \mathrm{c}$ \\
\hline L5 & $65 c$ & $60 \mathrm{~d}$ & $62 \mathrm{~b}$ & $300 \mathrm{~b}$ \\
\hline
\end{tabular}

TABELA 2 - Resultados ${ }^{1}$ do teste de frio durante 3, 5 e 7 dias a $10^{\circ} \mathrm{C}$, realizadas nos lotes de ementes de algodão, cultivar Delta Pine - Acala 90.

\begin{tabular}{|c|c|c|c|}
\hline Tratamento & 3 dias & 5 dias & 7 dias \\
\hline \multicolumn{4}{|c|}{ - } \\
\hline \multicolumn{4}{|c|}{ Caixa com terra } \\
\hline Lote 1 & $2 a$ & $1 \mathrm{a}$ & $1 \mathrm{a}$ \\
\hline Lote 2 & $2 \mathrm{a}$ & $2 a$ & $0 \mathrm{a}$ \\
\hline Lote 3 & $2 \mathrm{a}$ & $0 \mathrm{a}$ & $0 \mathrm{a}$ \\
\hline Lote 4 & $5 a$ & $0 \mathrm{a}$ & $0 \mathrm{a}$ \\
\hline Lote 5 & $0 \mathrm{a}$ & $1 \mathrm{a}$ & $0 \mathrm{a}$ \\
\hline \multicolumn{4}{|c|}{ Rolo de papel com terra } \\
\hline Lote 1 & $40 \mathrm{ab}$ & $21 \mathrm{a}$ & $14 \mathrm{a}$ \\
\hline Lote 2 & $49 a$ & $26 a$ & $16 \mathrm{a}$ \\
\hline Lote 3 & $27 \mathrm{bc}$ & $20 a$ & $8 \mathrm{a}$ \\
\hline Lote 4 & $35 a b c$ & $21 a$ & $10 a$ \\
\hline Lote 5 & $24 \mathrm{c}$ & $16 \mathrm{a}$ & $6 \mathrm{a}$ \\
\hline \multicolumn{4}{|c|}{ Rolo de papel sem terra } \\
\hline Lote 1 & $58 \mathrm{~b}$ & $67 \mathrm{ab}$ & $59 a b$ \\
\hline Lote 2 & $74 a$ & $80 a$ & $69 a$ \\
\hline Lote 3 & $45 \mathrm{bc}$ & $51 \mathrm{~b}$ & $37 \mathrm{bc}$ \\
\hline Lote 4 & $55 \mathrm{~b}$ & $33 c$ & 39 bc \\
\hline Lote 5 & $38 c$ & $58 \mathrm{~b}$ & $25 \mathrm{c}$ \\
\hline
\end{tabular}

${ }^{1}$ Médias seguidas por letras distintas, dentro de cada metodologia, diferem pelo teste de tukey, a $5 \%$. 
Medina \& Marcos Filho (1990) afirmaram que o teste de frio sem a utilização de terra, apesar de proporcionar efeitos menos drásticos às sementes de milho e resultados menos variáveis em relação ao teste de frio com terra, permite identificar, principalmente, as diferenças acentuadas no vigor das sementes.

Para que um teste de vigor seja amplamente utilizado, deve apresentar possibilidade de padronização da metodologia e de interpretação de resultados, além de características como reprodutibilidade de resultados, rapidez, objetividade, simplicidade, viabilidade e relações com outros testes de vigor (Association of Official Seed Analysts, 1983). Dentre os procedimentos estudados, o uso de rolo de papel sem terra com período de exposição ao frio de cinco dias (TABELA 2) é o mais indicado, por apresentar vantagens, como maior simplicidade, menor utilização de mão de obra e ocupar menos espaço, devido a não utilização de terra, que é um dos fatores que mais contribuem para a dificuldade de padronização do teste de frio entre laboratórios. Além disso, pode reduzir em dois dias o tempo de duração do teste, contribuindo para que decisões quanto ao destino de determinados lotes de sementes, possam ser tomadas mais rapidamente.

Outra vantagem desse procedimento é a confirmação da classificação dos lotes, em relação ao potencial fisiológico, obtida nos testes de envelhecimento acelerado e condutividade elétrica (TABELA 1), verificando-se a confiabilidade nos resultados fornecidos, além de permitir uma interpretação fácil dos mesmos.

A identificação de lotes com diferenças de vigor intermediário pode sofrer variações em função da metodologia adotada, pricipalmente quando de trata de lotes com diferenças pouco acentuadas (Marcos Filho et al., 1986). Dessa forma, verifica-se a importância do uso de mais de mais de um teste para determinar o vigor dos lotes de semente, em função da influência dos procedimentos adotados e do uso de situações específicas de estresse para estimar o comportamento relatico dos lotes em campo (Carvalho \& Nakagawa, 2000).

De maneira geral, os procedimentos de rolo de papel com terra e sem terra com períodos de exposição ao frio de três e sete dias apresentaram resultados relacionados entre si, mas não com os outros testes de vigor. Já o procedimento de rolo de papel sem terra com cinco dias de exposição ao frio se relacionou com os testes de envelhecimento acelerado e de condutividade elétrica, mostrando ser o mais promissor para avaliar os lotes de sementes de algodão e separá-los em diferentes níveis de vigor. Os procedimentos de caixa com terra, mostraram-se muito drásticos, impossibilitando a separação adequada dos lotes.

Portanto, o uso de rolo de papel sem terra com período de exposição ao frio de cinco dias (TABELA 2), é o mais indicado para a avaliação do potencial fisiológico de sementes de algodão, em relação às outras metodologias estudadas.

\section{REFERÊNCIAS BIBLIOGRÁFICAS}

ASSOCIATION OF OFFICIAL SEED ANALYSTS. Seed vigour testing handbook. East Lasing: AOSA, 1983. 93p. (Contribution, 32).

BARROS, S.R.B.; DIAS, M.C.L.L.; CICERO, S.M.; KRZYZANOWSKI, F.C. Teste de frio. In: KRZYZANOWSKI, F.C.; VIEIRA, R.D.; FRANÇA NETO, J.B. (Ed.) Vigor de sementes: conceitos e testes. Londrina: ABRATES, 1999. p.5.1-5.15.

BRASIL. Ministério da Agricultura. Regras para análise de sementes. Brasília: SNAD, DNDV, CLAV, 1992. 365p.

BRUGGINK, H.; KRAAK, H.L.; BEKENDAM, J. Some factors affecting maize (Zea mayz L.) cold test results. Seed Science and Technology, v.19, p.15-23, 1991.

BURRIS, J.S.; NAVRATIL, R.J. Relationship between laboratory cold test methods and field emergence in maize inbreds. Agronomy Journal, v.71, p.985-988, 1979.

CARVALHO, N.M.; NAKAGAWA, J. Sementes: ciência, tecnologia e produção. Jaboticabal: FUNEP, 2000. 588p.

CASEIRO, R.F.; MARCOS FILHO, J. Procedimentos para a condução do teste de frio visando a avaliação do vigor de sementes de milho. Scientia Agricola, v.57, p.459-466, 2000.

CICERO, S.M.; VIEIRA, R.D. Teste de frio. In: VIEIRA, R.D.; CARVALHO, N.M. (Ed.) Testes de vigor em sementes. Jaboticabal: FUNEP, 1994. p.151-164.

CROSIER, W.F. Fungi envolved and methods of conducting cold tests. Proceedings of the Association of Official Seed Analysts, v.47, p.185-190, 1957.

HOPPE, P.E. Correlation between corn germination in laboratory cold tests and stands in the field. Plant Disease Reporter, v.40, p.887-889, 1956.

KRZYZANOWSKI, F.C. Factors affecting the germination and emergence of cotton seed. Mississippi State, 1980. 106p. Tese (Ph.D) - Mississippi State University.

KULIK, N.M.; YAKLICH, R.W.; GARCIA, R.L. The influence of soybean foliar fertilization on the results of several laboratory and greenhouse of tests of seed germination and vigor and seed-borne fungal infection. Seed Science and Technology, v.10, p.321-325, 1982.

LOEFFLER, T.M.; MEYER, J.L.; BURRIS, J.S. Comparison of two test procedures for use in maize drying studies. Seed Science and Technology, v.13, p.653-658, 1985.

MARCOS FILHO, J. Conceitos e testes de vigor para sementes de soja. In: CONGRESSO BRASILEIRO DE SOJA. Londirna, 1999. Anais. Londrina: Embrapa Soja, 1999a. p.220-226.

MARCOS FILHO, J. Teste de envelhecimento acelerado. In: KRZYZANOWSKI, F.C.; VIEIRA, R.D.; FRANÇA NETO, J.B. (Ed.) Vigor de sementes: conceitos e testes. Londrina: ABRATES, 1999b. p.3.1-3.24.

MARCOS FILHO, J.; CARVALHO, R.V.; CICERO, S.M.; DEMÉTRIO, C.G.B. Qualidade fisiológica e comportamento de sementes de soja no armazenamento e no campo. Anais da ESALQ, v.43, p.389-443, 1986.

MARCOS FILHO, J.; CICERO, S.M.; SILVA, W.R. Avaliação da qualidade das sementes. Piracicaba: FEALQ, 1987. 230p.

MEDINA, P.F.; MARCOS FILHO, J. Avaliação da qualidade fisiológica das sementes de milho (Zea mays L.). Anais da ESALQ, v.47, p.47-70, 1990.

MIGUEL, M.H.; CICERO, S.M. Teste de frio na avaliação de sementes de feijão. Scientia Agricola, v.56, p.1233-1243, 1999. Suplemento.

MOLINA, J.C.; IRIGON, D.L.; ZONTA, E.P. Comparação entre metodologias do teste de frio na avaliação da qualidade fisiológica de sementes de milho (Zea mays L.). Revista Brasileira de Sementes, v.3, p.77-85, 1987. 
NOVEMBRE, A.D.L.C. Estudo da metodologia para a condução do teste de germinação em sementes de algodão (Gossipium hirsutum L.) deslintadas mecanicamente. Piracicaba, 1984. 133p. Tese (Doutorado) - Escola Superior de Agricultura "Luiz de Queiroz", Universidade de São Paulo.

NOVEMBRE, A.D.L.C.; MARCOS FILHO, J. Estudo da metodologia para condução do teste de germinação em sementes de algodão deslintadas mecanicamente. Revista Brasileira de Sementes, v.21, p.197-193, 1999.

SAMIMY, C.; TAYLOR, A.G.; KENTY, T.J. Relationship of germination of vigor tests to field emergence of snap beans (Phaseolus vulgaris L.). Journal of Seed Technology, v.11, p.23-34, 1987.

VIEIRA, R.D.; KRZYZANOWSKI, F.C. Teste de condutividade elétrica. In: KRZYZANOWSKI, F.C.; VIEIRA, R.D.; FRANÇA NETO, J.B. (Ed.) Vigor de sementes: conceitos e testes. Londrina: ABRATES, 1999. p.4.1-4.26.
VIEIRA, R.D.; TEKRONI, D.M.; EGLI, D.B. Effect of drought and defoliation stress in the field soybean seed germination and vigor. Crop Science, v.32, 471-475, 1992.

WATERS, L.; BLANCHETTE, L.B. Prediction of sweet corn field emergence by conductivity and cold tests. Journal of the American Society for Horticultural Science, v.108, p.778$781,1983$.

WOLTZ, J.M.; TEKRONY, D.M.; EGLI, D.B.; VINCELLI, P. Corn cold test germination as influenced by soil moisture, temperature and pathogens. Seed Technology, v.20, p.5670, 1998.

ZONTA, E.P.; MACHADO, A.A. Sistema de análise estatística para microcomputadores - SANEST. Pelotas: UFPel, 1984. 90p.

Recebido em 06.09.00 